\title{
Corrigendum
}

\section{Corrigendum to "Advanced Hepatic Fibrosis in Fatty Liver Disease Linked to Hyperplastic Colonic Polyp"}

\author{
Mahmud Mahamid, ${ }^{1,2}$ Omar Abu-Elhija, ${ }^{1,2}$ Tarik Yassin, ${ }^{3}$ and William Nseir ${ }^{2,4}$ \\ ${ }^{1}$ Internal Medicine Department, Holy Family Hospital, Nazareth, Israel \\ ${ }^{2}$ Faculty of Medicine in the Galilee, Bar-Ilan University, Safed, Israel \\ ${ }^{3}$ Internal Medicine Department, The Baruch Padeh Medical Center, Poriya, Israel \\ ${ }^{4}$ Internal Medicine Department, EMMS Nazareth Hospital, Nazareth, Israel
}

Correspondence should be addressed to Mahmud Mahamid; mahmudmahamid@yahoo.com

Received 19 November 2017; Accepted 27 November 2017; Published 28 December 2017

Copyright (C) 2017 Mahmud Mahamid et al. This is an open access article distributed under the Creative Commons Attribution License, which permits unrestricted use, distribution, and reproduction in any medium, provided the original work is properly cited.

The article titled "Advanced Hepatic Fibrosis in Fatty Liver Disease Linked to Hyperplastic Colonic Polyp" [1] uses the same cohort and study population as Mahamid et al., "Association between Fatty Liver Disease and Hyperplastic Colonic Polyp," The Israel Medicine Association Journal, Volume 19, Number 2, February 2017 [2]. This was raised by Ribaldone et al. [3]. The authors apologize for not citing this article and not discussing its relationship with their work.

The two articles are similar regarding the study population, but there is a significant difference between them regarding the main findings; the first article published at IMAJ showed the association between the two diseases. The second published at CJGH showed novel and interesting association between the degree of fibrosis in steatohepatitis (not the disease itself) and hyperplastic polyp.

\section{References}

[1] M. Mahamid, O. Abu-Elhija, T. Yassin, and W. Nseir, "Advanced hepatic fibrosis in fatty liver disease linked to hyperplastic colonic polyp," Canadian Journal of Gastroenterology and Hepatology, vol. 2017, Article ID 2054871, 5 pages, 2017.

[2] M. Mahamid, T. Yassin, O. Abu-Elheja, and W. Nseir, "Association between fatty liver disease and hyperplastic colonic polyp," The Israel Medicine Association Journal, vol. 19, no. 2, pp. 105108, 2017

[3] D. G. Ribaldone, G. M. Saracco, and R. Pellicano, "Comment on "advanced hepatic fibrosis in fatty liver disease linked to hyperplastic colonic polyp"," Canadian Journal of Gastroenterology and Hepatology, vol. 2017, Article ID 4083272, 2 pages, 2017. 




The Scientific World Journal


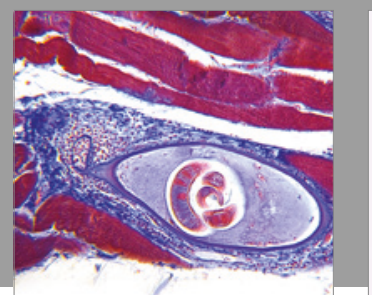

Gastroenterology Research and Practice
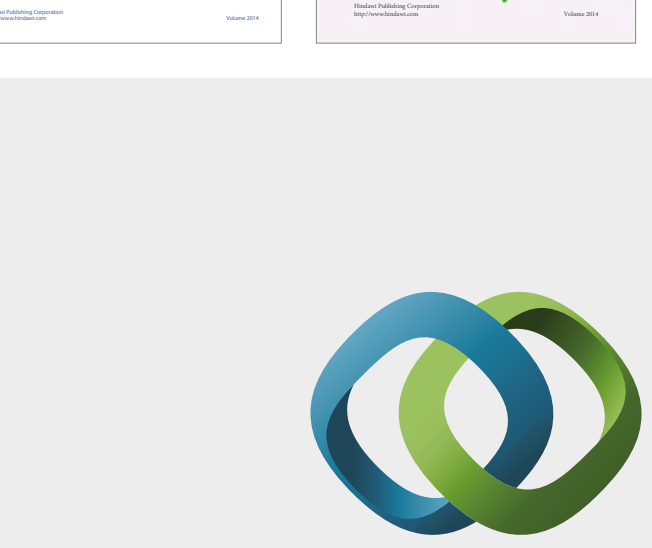

\section{Hindawi}

Submit your manuscripts at

https://www.hindawi.com
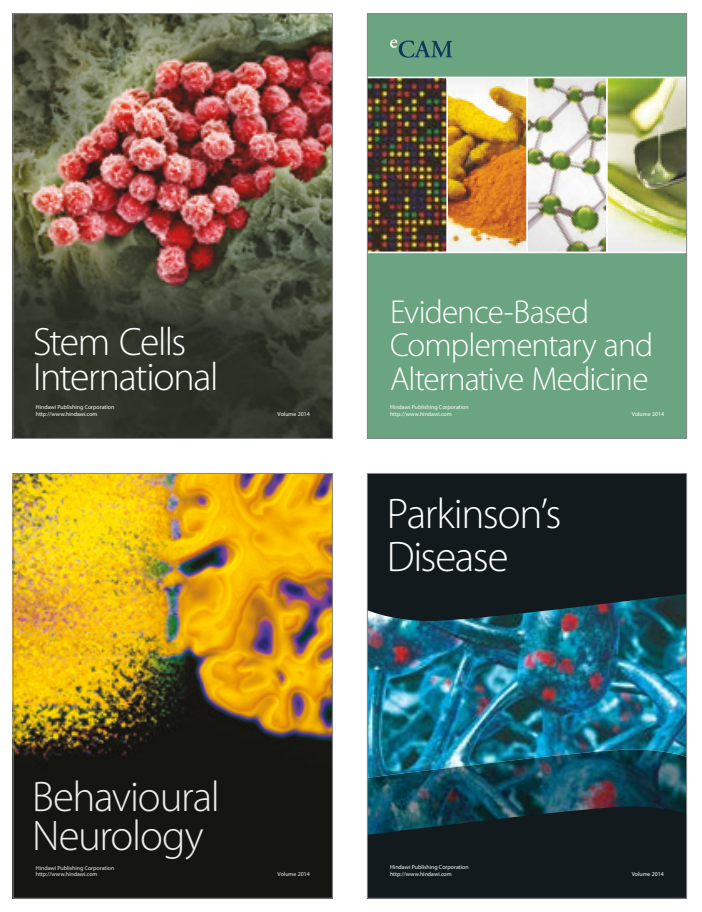
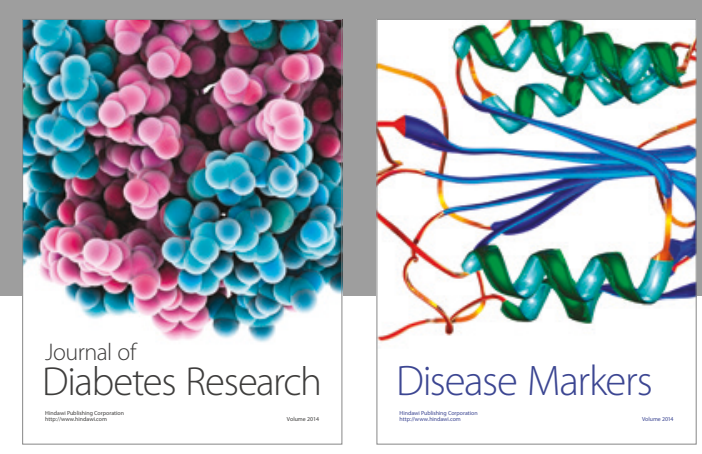

Disease Markers
